\title{
Harm, ethics committees and the gene therapy death
}

\author{
Julian Savulescu Murdoch Childrens Research Institute, Australia
}

The recent tragic and widely publicised death of Jesse Gelsinger in a gene therapy trial has many important lessons for those engaged in the ethical review of research. One of the most important lessons is that ethics committees can give too much weight to ensuring informed consent and not enough attention to minimising the harm associated with participation in research. The first responsibility of ethics committees should be to ensure that the expected harm associated with participation is reasonable.

Jesse was an 18-year-old man with a mild form of ornithine transcarbamylase (OTC) deficiency, a disorder of nitrogen metabolism. His form of the disease could be controlled by diet and drug treatment. On September 131999 a team of researchers lead by James Wilson at the University of Pennsylvania's Institute for Human Gene Therapy (IHGT) injected $3.8 \times 10^{13}$ adenovirus vector particles containing a gene to correct the genetic defect. He was the eighteenth and final patient in the trial. The virus particles were injected directly into the liver. $\mathrm{He}$ received the largest number of virus particles in a gene therapy trial. ${ }^{1}$ Four days later he was dead from what was probably an immune reaction to the virus vector. This was the first death directly attributed to gene therapy. It resulted in worldwide publicity, an independent investigation, the Federa Drug Administration (FDA) suspending all trials at the IHGT, an FDA, and a senate subcommittee investigation.

At a special public meeting at the National Institutes of Health (NIH) in December 1999, James Wilson, also the director of the IHGT, said they still did not understand fully what had gone wrong. Even though a massive dose had been used, only $1 \%$ of transferred genes reached the target cells. (None of the patients in the trial showed significant gene expression. Art Caplan, the University of Pennsylvania's outspoken bioethicist, is reported to have said: "if you cured anyone from a Phase 1 trial, it would be a miracle" and "there was never a chance that anyone would benefit from these experiments". ${ }^{3}$ ) Wilson claimed the death was the result of an anomalous response. Jesse's bone marrow had very low levels of red blood cell precursors, which probably predated the experiment. This may have reflected another genetic defect or a parvovirus infection. While most gene therapists at the meeting agreed that Jesse's response was unusual, some claimed it was foreseeable, given the ability of adenovirus to elicit an immune response and the high dose employed. ${ }^{2}$

The death also resulted in a wrongful death lawsuit which alleged ${ }^{3}$ :

- that members of the IHGT team and others were careless, negligent and reckless in failing to adequately evaluate Jesse's condition and eligibility. Jesse had an ammonia level 30\%-60\% higher than the eligibility criterion stated in the protocol approved by the FDA;

- that the adenovirus vector was unreasonably dangerous;

- that storage of the vector for 25 months led researchers to underestimate its potency;

- that a conflict of interest existed. Researchers and members of the University of Pennsylvania held patents covering several aspects of the technology employed. Wilson and colleagues also hold equity holdings in Genovo, the private sector biotechnology collaborator in the project. These conflicts of interest were alleged to have not been disclosed to the participant;

- that researchers failed to notify the FDA of adverse events in prior patients and animals.

The lawsuit also named Art Caplan, director of the University of Pennsylvania's Bioethics Center. It was also suggested but not explicitly alleged that Caplan had a conflict of interest because his centre was funded by Wilson's department. The complaint also drew attention to Caplan's intervention to persuade Wilson and others to use older participants who could consent (but who had a mild form of the disease) rather than newborns who could not consent (but had an otherwise lethal form of the disease). ${ }^{3}$

Other concerns related to this trial have included $^{4}$ :

- Researchers continued to increase the dose despite signs of toxicity in other patients;

- Volunteers were recruited by direct appeal on a patient advocacy website which described "very 
low doses" and "promising results". Such appeals had been rejected by federal officials as being coercive.

- The original consent reviewed publicly by the NIH mentioned that monkeys had died from the treatment but the final version did not mention that.

- The NIH's Recombinant DNA Advisory Committee (RAC) discussed the potential for lethal liver inflammation related to this experiment in December 1995, after reviewing toxicity results in rhesus monkeys and the death of one monkey from an extremely high dose of a first-generation vector. They recommended administration through a peripheral vein rather than directly into the liver. Food and Drug Administration regulators were concerned about infection of reproductive cells (germ line modification) and made researchers go back to direct liver injection.

In February 2000, at a senate hearing, Paul Gelsinger, Jesse's father, asserted:

1. that his son had not been told important preclinical evidence of toxicity (including the deaths of monkeys);

2. that his son was led to believe that his participation would be clinically beneficial, despite this being a Phase 1 trial where no benefit was envisaged. $^{5}$

James Wilson while acting as director of the IHGT, was also involved in several clinical trials and basic research. Judith Rodin, the University of Pennsylvania's president and William Danceforth, the lead author of an independent report into Jesse's death, said that Wilson was "overloaded". ${ }^{6}$ The IHGT has been downsized and no longer conducts clinical trials. The Department of Health and Human Services has said it intends to introduce laws which will fine researchers up to $\$ 250,000$ and institutions up to one million dollars for failing to meet new stricter standards. ${ }^{6}$

\section{Interesting insights}

This experiment yields many interesting insights into the problems related to ethics review of research in general. But there is perhaps one lesson which is more important than all the others. Research ethics review is concerned primarily with two goals: ensuring that the expected harm involved in participation is reasonable and that participants give valid consent. The requirement to give valid consent has led many in the research ethics community to suggest that non-therapeutic research on incompetent patients is unethical. This trial illustrates par excellence the increasing and mistaken tendency of ethics committees to give too much weight to consent and to fail to give sufficient attention to protecting participants from harm.

One simple justification for conducting this trial in adults with the mild form of the disease rather than severely affected newborns goes like this.
"There are serious risks including a risk of death associated with participation in this trial. Since the risks are significant, it is better that the trial be conducted on humans who consent to those risks rather than on those who cannot consent."

However, it is important to distinguish between the chance of a bad outcome occurring and expected harm. Expected harm is the probability of a harm occurring multiplied by the magnitude of that harm. Being harmed by an intervention is being made worse off than one would otherwise have been if that intervention had not been performed.

\section{QALY approach}

Consider an illustration using a quality adjusted life year (QALY) approach. Let's assume for simplicity's sake that the only harm in this experiment was death from the virus vector. Let's assign a value of 1 to perfect health and 0 to death. Jesse's existing quality of life was less than perfect, but still acceptable. Let's say it was 0.8 . Assume that he would have lived another 50 years. Assume that the risk of the gene therapy killing him was small-1/10 000 (this is a conservative estimate: Jesse's death was the first death in nearly 400 gene therapy trials involving over 4000 patients). ${ }^{7}$ That means that the expected harm of Jesse participating was $0.8 \mathrm{X}$ $50 / 10000=40 / 10000=0.004$ quality adjusted life year. This is a very small expected harm.

Now compare this to the expected harm that severely affected newborns would experience. Imagine that a newborn boy, who is already very likely to die of his disease, dies as a result of a similar gene therapy trial. Has he been harmed? He is not worse off than he would otherwise have been, since he would have died if the trial had not been conducted. He would have died of the severe form of the underlying disease. The magnitude of the expected harm to adult participants with milder forms of this disease was significantly greater than to newborns with the severe form of the disease.

Put simply, fesse had something to lose while the seriously affected newborn did not. Even though the expected harm to Jesse prior to commencing the trial may have been small, why prefer a small expected harm to no harm? There is no good reason, regardless of whether someone is prepared to consent. It is irrational to prefer more harm to less harm.

The ethics committee which persuaded Wilson and colleagues to invite adults to participate either:

1. misunderstood the nature of expected harm and/or ethics committees' responsibilities in evaluating it, or

2. (more likely) gave greater weight to consent than to expected harm.

Attempting to draw lessons from Jesse's death, Friedmann, director of the Program in Human Gene Therapy at the University of California, stated: "The single most important mechanism for ensuring patient protection from inherent risks of clinical experiments, unrealistic expectations, and 
potential conflicts of interest of the investigator is accurate and full disclosure of potential risks and benefits and a well-executed informed consent process". 8

Fine rhetoric but probably false. In Jesse's case, there were allegedly significant omissions in the consent process, allegedly involving failure to disclose relevant risks and conflicts of financial interest. But would these have made a difference? Jesse understood the trial would not cure him and there was a small chance it could hurt him. But, as his father said: "He wanted to help the babies . . . . My son had the purest intent". Indeed, strong intentions. He attempted to enrol when he was 17 but had to return when he turned 18 and was eligible. ${ }^{7}$ Even if Jesse Gelsinger would not have participated if disclosure had been more frank, someone would have. (After all, one healthy person offered his own heart when Barney Clark received the first artificial heart!) The key to research review is not only consent, but a responsible objective evaluation of the reasonableness of harm in research.

There are complex issues about whether this trial should have been conducted on human beings at all. But if it was justified, it would have been better to conduct it on newborns with the severe form of the disease. Sometimes it is better that an incompetent person participate in research than a competent person who can consent. Consent is important. But the fact that a human being is not able to consent should not paralyse ethics committees. It is a mistake to give more weight to consent than to expected harm. Ethics committees must make an evaluation of the expected harm and whether less harmful avenues should be pursued.

\section{References}

1 Lehrman S. Virus treatment questioned after gene therapy death. Lancet 1999;401:517-8

2 Marshall E. Gene therapy death prompts review of adenovirus vector. Science 1999;286:2244-5.

3 Fox JL. Gene-therapy death prompts broad civil lawsuit. Nature Biotechnology 2000;18:1136.

4 Nelson D, Weiss R. Is Jesse's death a stain on the new science? The Age 1999 Dec 5: news section: 1.

5 Walters L. "Gene therapy: overview". In: Murray T, Mehlman MJ, eds. Encyclopedia of ethical, legal and policy issues in biotechnology. New York: Wiley, 2000: 341.

6 Smaglik P. Clinical trials end at gene therapy institute. Nature 2000;405:497.

7 Verma IM. A tumultuous year for gene therapy. Molecular Therapy 2000;2:415-6.

Therapy 2000,2:415-6. Science 2000;287:2163-5.

Science 2000;287:2163-5.
Savulescu J. Safety of participants of non-therapeutic research Savulescu J. Safety of participants of non-therapeutic resear
must be ensured. British Medical fournal 1998;16:891-2.

\section{1st Asia Pacific Forum on Quality Improvement in Health Care}

\section{Three day conference}

\section{Wednesday 19 to Friday 21 September 2001 \\ Sydney, Australia}

We are delighted to announce this forthcoming conference in Sydney. Delegate enquiries are welcome.

The themes of the Forum are:

- Improving patient safety

- Leadership for improvement

- Consumers driving change

- Building capacity for change: measurement, education and human resources

- The context: incentives and barriers for change

- Improving health systems

- The evidence and scientific basis for quality improvement.

Presented to you by the BMJ Publishing Group (London, UK) and Institute for Healthcare Improvement (Boston, USA), with the support of the the Commonwealth Department of Health and Aged Care (Australia), Safety and Quality Council (Australia), NSW Health (Australia), and Ministry of Health (New Zealand).

For more information contact: quality@bma.org.uk or fax +44 (0)20 73836869 